\title{
Delayed successful treatment of iatrogenic colon perforation using an over-the-scope clip
}

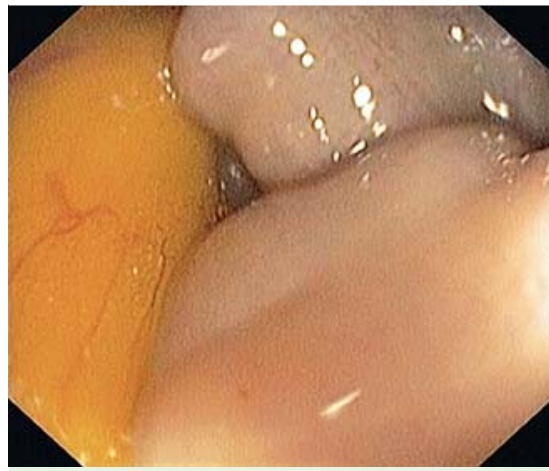

Fig. 1 Colon perforation with visualization of the epiploon.

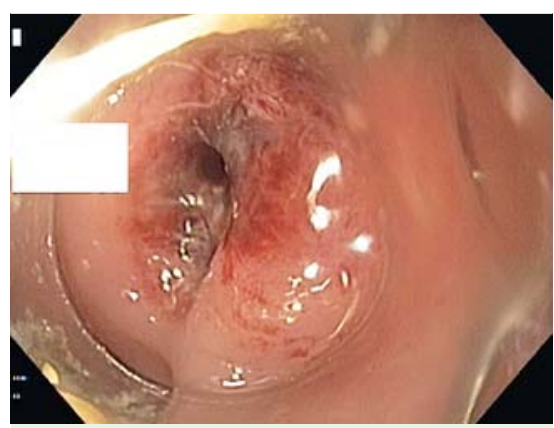

Fig. 2 Perforation orifice and 11/6t over-thescope clip.

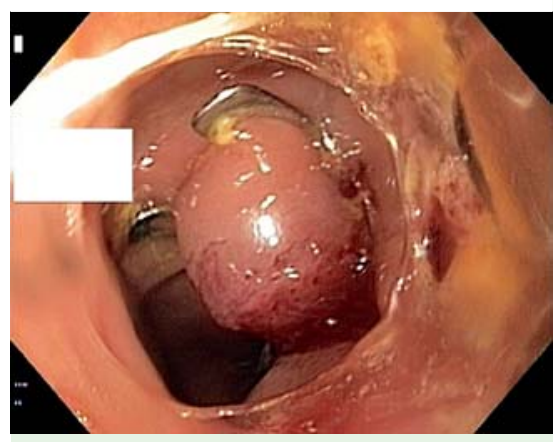

Fig. 3 Over-the-scope in place.

Over-the-scope clip closure of iatrogenic gastrointestinal tract perforations has been successfully demonstrated, and is usually performed in the immediate peroperative setting $[1,2]$. We report the first case, to our knowledge, of delayed successful treatment of an iatrogenic colon perforation using an over-the-scope clip. An 80-year-old woman underwent routine colonoscopy. Her medical history was unremarkable apart from unex-

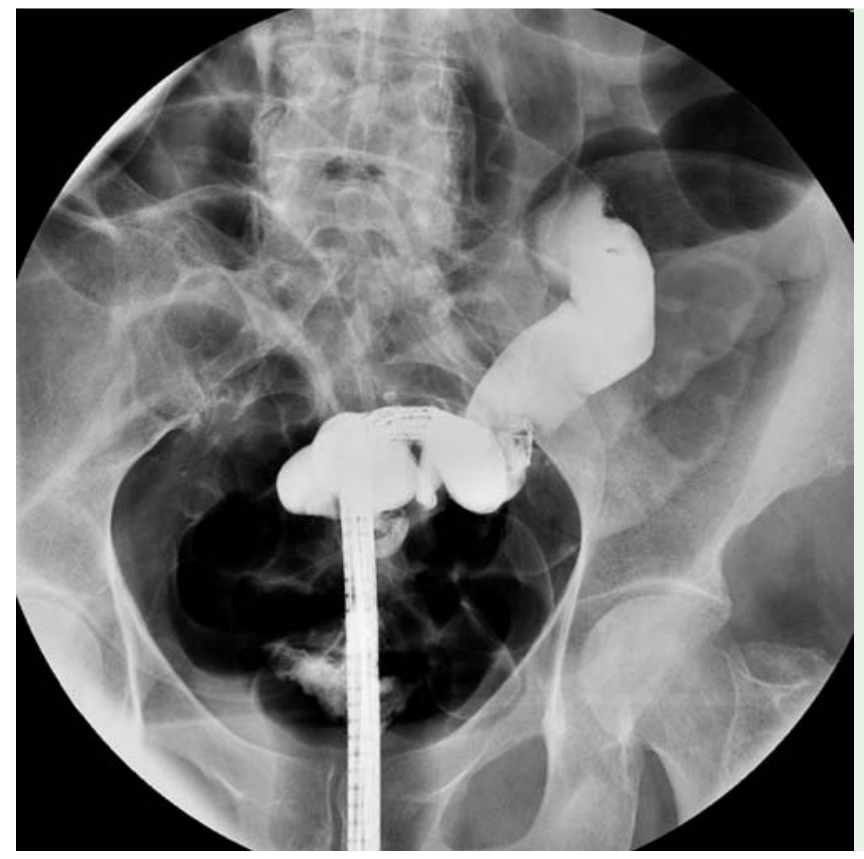

Fig. 4 Watertight closure with no extravasation of contrast medium.

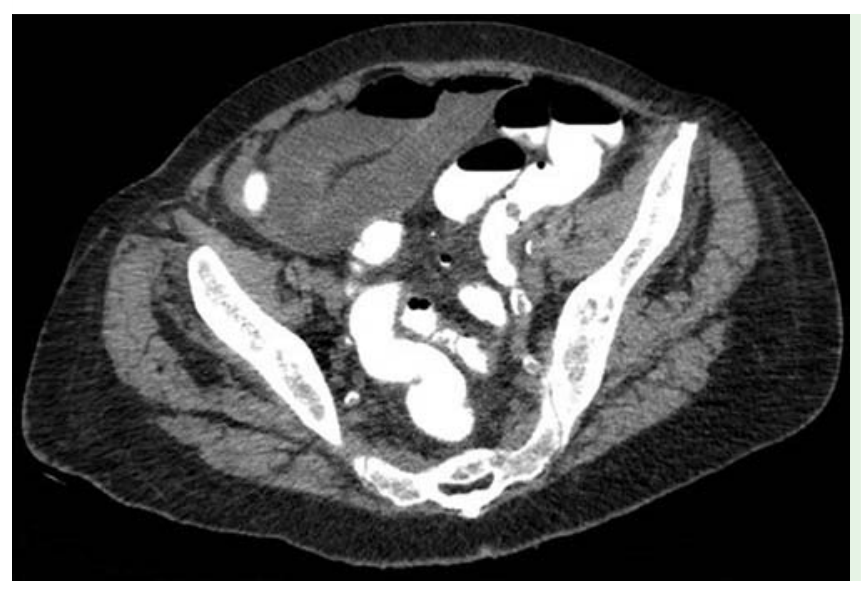

Fig. 5 CT scan with bowel opacification confirmed a sealed clip.

plained thrombocytopenia (40000 platelets/dL). During endoscopy, a perforation occurred at the level of the sigmoid junction with the left colon ( $\bullet$ Fig. 1). At that time, after multidisciplinary discussion, and in view of the successful colonic preparation and the thrombocytopenia, a mini-invasive endoscopic treatment was proposed (the patient being on antibiotics). Two and a half hours later the patient was transferred to our unit for an attempt at clip closure. Using a gastroscope and $\mathrm{CO} 2$ insufflation, a 7-mm perforation orifice was visualized. An OTSC 11/6t clip (Ovesco Endoscopy GmbH, Tübingen, Germany) was then delivered, with aspiration of the edges of the orifice ( Fig.2, Fig.3). Contrast medium study through the endoscope performed at that time did not show any fluid extravasation ( $\bullet$ Fig. 4 ).

The day after the procedure, the patient presented localized peritoneal irritation and fever $\left(38^{\circ} \mathrm{C}\right)$. Lab tests showed no hyperleukocytosis, but the C-reactive protein level had increased to 204 U/L. Spiral CT with bowel opacification performed then confirmed a sealed clip closure with no free fluid or air in the peritoneal cavity ( Fig.5). The patient was kept fasting until bowel transit was re-established 2 days later. She was symptom-free by the 
postoperative third day. On day 5 , she was discharged from the hospital. She is clinically well and symptom-free.

Delayed treatment of an iatrogenic colonic perforation with an over-the-scope clip is a feasible and effective technique that should be considered by expert endoscopists. However, the peritoneal cavity may become contaminated during the delay between perforation and definitive treatment.

Endoscopy_UCTN_Code_TTT_1AQ_2AG

Competing interests: None
Gianfranco Donatelli ${ }^{1}$, Bertrand M.

Vergeau ${ }^{1}$, Jean-Loup Dumont ${ }^{1}$, Claude Altmann', Stravros Dritsas ${ }^{2}$, Parag Dhumane ${ }^{3}$, Thierry Tuszynski ${ }^{1}$, Bruno Meduri ${ }^{1}$

${ }^{1}$ Unité d'Endoscopie Interventionnelle, Hôpital Privé des Peupliers, Générale de Santé, Paris, France

2 Service d'Hépatologie, Hôpital Minjoz, Besançon, France

${ }^{3}$ Department of General and Laparoscopic Surgery, Lilavati Hospital and Research Center, Bandra (W), Mumbai, India

\section{References}

1 Donatelli G, Vergeau BM, Dritsas $S$ et al. Closure with an over-the-scope-clip allows therapeutic ERCP to be safely performed after acute duodenal perforation during diagnostic endoscopic ultrasound. Endoscopy 2013; 45: E392 - 393

2 Diez-Redonod P, Bianco JL, Lorenzo-Pelayo S et al. A novel system for endoscopic closure of iatrogenic colon perforations using the Ovesco clip and omental patch. Rev Esp Enferm Dig 2012; 104: 550-552

\section{Bibliography}

Dol http://dx.doi.org/

10.1055/s-0034-1365796

Endoscopy 2014; 46: E285-E286

(c) Georg Thieme Verlag KG

Stuttgart · New York

ISSN 0013-726X

\section{Corresponding author}

\section{Dr. Gianfranco Donatelli}

Hôpital Privé des Peupliers, Générale de Santé

8 Place de l'Abbé G. Hénocque

75013 Paris

France

donatelligianfranco@gmail.com 